\title{
IPTEKS PENGELOLAAN PIUTANG PADA DEPARTEMEN SERVIS DI PT. ASTRA INTERNATIONAL ISUZU SALES OPERATION CABANG MANADO
}

\author{
Elma Natasha Mangayuk ${ }^{1}$, Rudy J. Pusung ${ }^{2}$ \\ ${ }^{1,2}$ Jurusan Akuntansi, Fakultas Ekonomi dan Bisnis Universitas Sam Ratulangi, Jl. Kampus Unsrat, Manado, \\ 95115, Indonesia
}

Email: enmangayuk@gmail.com

\begin{abstract}
PT Astra Isuzu is part of Astra's automotive group. In carrying out its business, the company has three departements namely unit sales departement, service departement, and spare part sales departement. This research is about managing receivables in the service departement at PT Astra Isuzu, Manado branch. In the service department of PT Astra Isuzu the Manado branch has five types of customers. therefore the company must pay attention to several things in managing its receivables according to the type of customer who has obligations. There are three stages that must be carried out by the company in managing its receivables in order to avoid uncollectible receivables, namely the company must know the condition of the cause of the receivables, the company must understand the administrative process, and must ensure the repayment of the accounts. PT Astra Isuzu also makes a account receivable protection policy for customers who are always late in paying their obligations. In this case, PT Astra Isuzu Manado branch is good enough in managing its service receivables, but the company needs to pay more attention to the division of tasks specifically in terms of collection of receivables.
\end{abstract}

Keywords : Receivables, Managing Receivables, Account Receivable Protection

\section{PENDAHULUAN}

Pada saat ini banyak kalangan masyarakat yang sedang disibukkan oleh urusan hutang piutang akibat transaksi jual beli secara kredit. Beberapa perusahaan besar telah menerapkan penjualan secara kredit. Hal ini dilakukan dengan maksud agar masyarakat yang melakukan pembelian tidak merasa terbebani saat melakukan proses pembayaran atas barang atau jasa. Pelanggan yang melakukan pembelian secara kredit artinya memiliki kewajiban terhadap perusahaan yang memberikan penjualan secara kredit. Sedangkan, pihak perusahaan akan mengakui kewajiban pelanggan sebagai piutang atau pendapatan yang harus diterima akibat dari terjadinya penjualan secara kredit. Pengertian piutang menurut Rusdi Akbar adalah meliputi semua hak atau klaim perusahaan pada seseorang atau organisasi lain untuk menerima sejumlah kas, barang, atau jasa di masa yang akan datang sebagai akibat kejadian pada masa yang lalu.

Piutang merupakan aset lancar perusahaan, namun juga dapat menjadi masalah bagi perusahaan apabila tidak dapat dikelola dengan baik. Untuk itu diperlukan pengelolaan piutang yang baik dari perusahaan agar tidak terjadi kerugian atas piutang tak tertagih. PT Astra International Isuzu Sales Operation Cabang Manado atau yang lebih dikenal dengan ISO Manado merupakan perusahaan yang bergerak dibidang jasa dan perdagangan. Aktivitas kerja perusahaan ini adalah penjualan unit, service, dan spare part.

Transaksi jual beli secara kredit banyak ditemukan pada departemen service PT Astra International Isuzu Sales Operation Cabang Manado. Akibat dari penjualan kredit adalah akan bertambahnya piutang yang harus ditagih oleh pihak perusahaan kepada pelanggan yang memiliki kewajiban. Jika di biarkan maka ada kemungkinan kerugian atas piutang tak 
tertagih. Maka dari itu dibutuhkan pengelolaan piutang yang baik agar tidak terjadi piutang tak tertagih.

\section{TINJAUAN PUSTAKA}

Pengertian Piutang. Menurut Kieso,dkk (2009, h.346) piutang adalah klaim uang, barang, atau jasa kepada pelanggan atau pihak-pihak lainnya. Untuk tujuan pelaporan keuangan, piutang diklasifikasikan sebagai lancar (jangka pendek) atau tidak lancar (jangka panjang), (Hiliyana dan Effendi). Sedangkan menurut Syamsuddin (2011:255), piutang terjadi karena adanya transaksi penjualan barang atau jasa secara kredit kepada pelanggan. (Ariyanti, Saifi, dan A. Z (2016). Jadi dapat disimpulkan bahwa piutang adalah klaim bagi pelanggan atau pihak-pihak lainnya akibat dari adanya transaksi penjualan atas barang dan jasa secara kredit.

Pengelolaan Piutang. Menurut Akmal (2009, h.303) "pengelolaan piutang meliputi tiga tahap. Tahap pertama, menyangkut kondisi yang menyebabkan timbulnya piutang. Yang kedua, mengenai administrasi dan pengorganisasian piutang. Tahap terakhir menyangkut pelunasan piutang".

\section{METODE DAN TEKNIK PENERAPAN IPTEKS}

\subsection{Metode Penerapan Ipteks}

Teknik ipteks yang diterapkan oleh penulis pada jurnal ipteks akuntansi bagi masyarakat ini adalah teknik pengelolaan piutang menurut Akmal (2009, h. 303). Menurut Akmal ada tiga hal penting yang harus diperhatikan oleh perusahaan dalam mengelola piutangnya agar tidak terjadi hal-hal yang merugikan perusahaan.

\subsection{Teknik Penerapan Ipteks}

Teknik ilmu pengetahuan, teknologi dan seni yang diterapkan adalah teknik pengelolaan piutang menurut Akmal (2009, h.303). Menurut Akmal (2009, h.303) Ada tiga hal penting yang harus di perhatikan oleh perusahaan dalam mengelola piutangnya yaitu, pertama dengan melihat kondisi yang menyebabkan timbulnya piutang, kedua administrasi dan pengorganisasian piutang, dan ketiga pelunasan piutang. Perusahaan harus memperhatikan tiga hal tersebut agar tidak terjadi kerugian atas piutang tak tertagih.

\section{PEMBAHASAN}

\subsection{Gambaran Umum Objek Penerapan Ipteks}

PT Astra International Isuzu Sales Opearation merupakan bagian dari salah satu perusahaan besar di Indonesia yaitu PT Astra International Tbk. PT Astra International Isuzu Sales Operation atau biasa disebut Astra Isuzu berdiri sejak tahun 1990 dimana sekarang kantor pusat Astra Isuzu beralamatkan di Jl. Danau Sunter Utara Block 03 Jakarta. PT Astra Isuzu saat ini memiliki 52 cabang Dealler yang tersebar di Indonesia. Dalam menjalankan bisinisnya, PT Astra Isuzu bekerja sama dengan PT Isuzu Astra Motor Indonesia selaku agen tunggal pemegang merk Isuzu. Dari 52 cabang Dealler Astra Isuzu salah satunya berada di Manado.

PT Astra Isuzu Cabang Manado sama seperti dengan Astra Isuzu cabang lainnya melakukan aktivitas penjualan unit, penjualan jasa service, dan penjualan spare part. Dalam melakukan aktivitasnya PT Astra Isuzu Cabang Manado dipimpin oleh seorang Kepala Cabang, yang dibantu oleh masing-masing kepala di tiap-tiap departmen, yaitu Kepala Administrasi pada Departemen Administrasi, Supervisor pada Departemen Unit, Kepala Bengkel pada Departemen Service, dan Kepala Part di Departement Part.

\subsection{Pembahasan}

PT Astra Isuzu Cabang Manado memiliki 3 jenis aktivitas kerja yaitu penjualan unit, penjualan jasa service, dan penjualan spare part. Dalam pembahasan ini akan fokus pada 
penjualan jasa service pada departemen service. Pada saat terjadi penjualan secara kredit maka akan timbul yang disebut piutang. Piutang akan berdampak positif jika dapat dilunasi sesuai dengan jangka waktu yang telah disepakati. Namun akan berbahaya jika tidak dapat dikelola dengan baik karena dapat mengakibatkan kerugian atas piutang yang tak tertagih. Untuk itu perusahaan membutuhkan pengelolaan piutang yang baik dengan cara mengikuti tahap-tahap pengelolaan piutang dan melakukan pengawasan piutang. Menurut Akmal (2009, h 303) ada tiga tahap dalam pengelolaan piutang yaitu :

Kondisi Penyebab Timbulnya Piutang. Terjadinya piutang di PT Astra Isuzu khusunya pada departemen servcie tergantung pada jenis pelanggannya. Terdapat lima jenis pelanggan pada Departemen Service PT Astra Isuzu Cabang Manado, yaitu : pelanggan PKS (Perjanjian Kerja Sama, Pelanggan Retail, Pelanggan Asuransi, Pelanggan PT IAMI, Pelanggan MU-X). Pada umumnya piutang terjadi akibat dari transaksi penjualan secara kredit dan itu berlaku pada pelanggan PKS, pelanggan retail dan pelangan asuransi. Pelanggan PKS dan pelanggan retail adalah jenis pelanggan ekstern yang memiliki kewajiban harus membayar kewajibannya pada waktu yang sudah di sepakati, maka dari itu sudah menjadi tugas bagi perusahaan untuk melakukan follow up tagihan. Sedangkan bagi, Pelanggan PT IAMI, dan Pelanggan MU-X adalah jenis pelangan Intern. Pelanggan intern adalah pelanggan yang merupakan bagian dari aktivitas bisnis PT Astra Isuzu. Sebagai contoh, pelanggan PT IAMI. PT IAMI adalah sebuah perusahaan yang memproduksi unit merk Isuzu yang akan di perdagangkan oleh PT Astra Isuzu. Mengapa PT IAMI bisa memiliki piutang terhadap PT Astra Isuzu? Jawabannya adalah karena PT IAMI memprogramkan Ipassport dan KSG yang mana program tersebut merupakan layanan service gratis bagi pelanggan ekstern yang mendaftarkan kartu garansi service. Tagihan pada PT IAMI dilakukan setiap 2 kali seminggu. Maka metode penagihan bagi pelanggan exteren dan pelanggan interen berbeda. Hal ini lah yang menjadi alasan bagi PT Astra Isuzu bahwa penting untuk mengetahui kondisi penyebab timbulnya piutang pada departemen service.

Administrasi dan Pengorganisasian Piutang. Pada departemen service di PT Astra Isuzu Cabang Manado akan melakukan administrasi ketika service advisor sudah melakukan pemeriksaan akhir terhadap perbaikan kendaraan pelanggan. Setelah service advisor melakukan pemeriksaan akhir maka tugas billing service untuk mencetak kwitansi dan faktur . Pada saat pelanggan memutuskan untuk melakukan piutang maka kwitansi dan faktur yang sudah dicetak akan dititip pada kasir. Kasir menerima kwitansi dan faktur, lalu melakukan pencatatan terhadap pertambahan saldo piutang dan akan dikurangkan sampai pelanggan melakukan pelunasan. Jika pembayaran dilakukan sesuai dengan nama dan total taggihan yang tertera di kwitansi maka kasir akan melakukan pencatatan terhadap pengurangan piutang. Namun, terkadang pelanggan melakukan pembayaran dengan transfer beda nama. Nama yang ada di rekening koran tidak sama dengan nama yang ada di kwitansi. Jika terjadi seperti itu, maka kasir akan melakukan pencatatan bahwa saldo piutang di pindahkan ke saldo piutang titipan. Hal ini juga dapat menyebabkan saldo piutang sepertinya masih ada padahal pelanggan sudah melakukan pembayaran. Solusinya PT Astra Isuzu melakukan BPH IN OUT. BPH In Out adalah sarana yang dilakukan untuk menghapuskan saldo piutang titipan dengan cara membatalkan kwitansi piutang titipan yang didukung oleh surat beda nama dari pelanggan yang kemudian akan dibuatkan BPH (Bukti Pencacatan Piutang) yang akan di setujui oleh kepala administrasi dan kepala cabang.

Pelunasan Piutang. Dalam melakukan penagihan untuk pelunasan piutang PT Astra Isuzu cabang Manado cukup baik, namun terkadang memiliki kendala. Datangnya kendalakendala tersebut dari pihak intern atau perusaahaan itu sendiri dan pihak ekstern atau dari pihak pelanggan. Kendala dari perusahaan sendiri yaitu terjadi karena tidak ada yang secara khusus diberikan tugas untuk melakukan penagihan piutang. Pada PT Astra Isuzu cabang Manado yang melakukan penagihan piutang adalah Admin Service dan Billing Service. 
Admin dan Billing Service karena memiliki banyak pekerjaan sehingga sulit untuk melakukan follow up tagihan piutang. Sedangkan kendala dari pihak eksteren atau pelanggan sendiri sering terjadi dan memiliki potensi yang tinggi untuk terjadinya piutang tak tertagih. Biasanya pada saat perusahaan sudah melakukan follow up tagihan piutang dengan baik namun banyak alasan dari pelanggan untuk tidak membayar kewajibannya. Alasan yang dimaksudkan seperti pelanggan belum menerima dokumen-dokumen piutang, padahal pihak perusahaan sudah mengirimkan dokumennya, kemudian ada juga yang beralasan bahwa dokumen tagihan sudah diproses namun masih menunggu tanda tangan bos, dll. Dengan melihat kondisi seperti ini, perusahaan melakukan improvement dimulai dari dalam perusahaan, yaitu dengan membuat daftar umur piutang dan membuat buku pembantu piutang. Daftar umur piutang digunakan untuk mengendalikan piutang dengan menyusun tabel umur piutang. Pada tabel umur piutang perusahaan dapat mengetahui jumlah saldo piutang, dan dapat menjadikan tabel umur piutang tersebut sebagai bahan untuk melakukan penagihan agar tidak terjadi piutang lewat jatuh tempo. Piutang dikendalikan agar dapat mengetahui kondisi piutang perusahaan, serta dapat mengetahui pelanggan yang rajin membayar piutang dan lambat membayar piutang bahkan ada yang sudah jauh lewat jatuh tempo. PT Astra Isuzu cabang Manado juga menerapkan metode AR Protect atau perlindungan piutang sebagai pengawasan piutang service mereka. AR protect yang diterapkan oleh perusahaan di ukur dari daftar umur piutang. AR Protect ini berlaku bagi pelanggan yang masih memiliki piutang alias belum bayar piutang lalu kemudian mau menambah piutangnya.

\section{KESIMPULAN DAN SARAN}

\subsection{Kesimpulan}

Pengelolaan Piutang pada PT Astra Isuzu Cabang Manado sudah dilakukan cukup baik. Dengan adanya kebijakan AR protect atau perlindungan piutang pada perusahaan maka akan meminimalisir terjadinya piutang tak tertagih.

\subsection{Saran}

Agar pengelolaan piutang dapat efisien dan efektif, maka perusahaan perlu lebih lagi dalam memahami kondisi penyebab timbulnya piutang, menguasai proses administrasi, dan memperhatikan pembagian tugas dalam melakukan penagihan piutang.

\section{DAFTAR PUSTAKA}

Ariyanti, R, Saifi, M. (2016, April). Analisis Pengelolaan Piutang Sebagai Upaya Untuk Menjaga Likuiditas dan Meningkatkan Rentabilitas Eccindo (Studi Pada Koperasi Karyawan PT. Ecco Indonesia Sidoarjo Periode 2012-2014). Jurnal Administrasi Bisnis(JAB), 33(2), 59-68.

Hiliyana, \& Effendi,R. (2015). Analisis Pengendalian Piutang Dagang Terhadap Efektivitas Arus Kas Pada CV. Union Motor. 1-8.

Husin, Maya; Effendi, Rizal;. (2010). Evaluasi Prosedur Pengelolaan Piutang Usaha Dalam Meminimalisir Piutang Tak Tertagih Pada PT. Bukit Ringgit Sejahtera Palembang Stie Mdp. 1-8.

Jamal, E. (2014). Analisis Pengelolaan Piutang Dagang Pada PT. Esham. 1-15.

Milda, V. (2013). Analisis Faktor-Faktor Penyebab Piutang. 1-10.

PT. Astra International Tbk. (2018). Astra International Beranda. Diambil Kembali Dari Astra International: https://www.astra.co.id

PT. Astra Isuzu. (2017). Profil PT. Astra Isuzu. Diambil kembali dari Astra Isuzu: https://www.astraisuzu.co.id 
Rositah, N., \& Handayani, S.R. (2018). Pengaruh Beban Piutang Tak Tertagih Terhada Return On Assets. Jurnal Administrasi dan Bisnis, 1-6.

Wardaningsih, S.S. (2011, Oktober). Analisis Pengelolaan Piutang Sebagai Tindak Lanjut. Jurnal Ekonomi dan Kewirausahaan, 11(2), 127-133.

Surono, BAA. (2015, November). Pengelolaan Piutang Yang Efektif Sebagai Upaya Meningkatkan Profitabilitas (Studi Kasus Pada Perusahaan CV Walet Sumber Barokah Malang Periode 2012-2014). Jurnal Administrasi Bisnis (JAB), 28(1), 1-10.

Ariani, Anita. (2017). Optimalisasi Manajemen Piutang Pada UD. Mitrasantika Furniture Di Surabaya. 1-10.

Timuriana, Tiara. (2014). Pengaruh Pengendalian Piutang Usaha dalam Meminimalkan Piutang Tak Tertagih Pada PT. Gaya Sastra Indah. Jurnal Ilmiah Manajemen dan Akuntansi Fakultas Ekonomi (JIMAFE), 90-97. 